\title{
$\mathrm{HEV} \mathrm{UV단자의} \mathrm{스트립} \mathrm{레이아웃과} \mathrm{금형설계에} \mathrm{관한} \mathrm{연구}$
}

\author{
최계광 ${ }^{1^{*}}$, 김세환 $^{1}$, 조윤호 $^{2}$ \\ ${ }^{1}$ 공주대학교 기계자동차공학부, ${ }^{2}$ (주)상진 미크론
}

\section{Study on the Strip Layout \& Die Design of HEV UV Terminal}

\author{
Kye-Kwang Choi $^{{ }^{*}}$, Sei-Hwan $\mathrm{Kim}^{1}$ and Yun-Ho $\mathrm{Cho}^{2}$ \\ ${ }^{1}$ Kongju National University. Div. of Mechanical \& Automotive Engineering. \\ ${ }^{2}$ Sangjin Micron co. Ltd.
}

요 약 본 논문에서는 HEV UV단자를 자동화 모듈인 씨마트론 다이 디자인을 활용하여 스트립 레이아웃설계를 $3 \mathrm{D}$ 로 하였다. 제품의 스탬핑을 원활하게 하기 위하여 스트립 레이아웃을 33.5 도 경사지게 수정하여 광폭 1 열 1 개 뽑 기의 내측캐리어를 단 배열로 블랭크 레이아웃을 최적화하였다. 1 개의 금형에서 두개의 단자를 공용으로 양산하기 위해 29개 공정으로 3D 스트립 레이아웃설계 및 금형설계를 완성하였다.

\begin{abstract}
The This research paper deals with research on the 3D strip layout design of HEV UV terminal by utilizing the Cimatron Die Design, an automation module. To ensure smooth stamping of the product, strip layout was corrected for 33.5 degrees of slope, and blank layout of the double-width, 1-line, 1-pull out inner carrier was then optimized as a single arrangement. To mass-produce two different terminals from one common die, 3D strip layout design and die design were completed in 29 different processes.
\end{abstract}

Key Words : Automation Module, Strip Layout, Blank Layout, Single Arrangement

\section{1. 서론}

하이브리드자동차(HEV)는 내연기관과 전기구동시스 템의 장점을 조합한 친환경 자동차로써 연료전지자동차 나 전기자동차와 같은 무공해 자동차는 아니다. 하지만 현재의 기술을 바탕으로 실용화가 가능하다는 점에서 어 느 친환경 자동차보다 현실성(시장성)을 확보하고 있다. 하이브리드(Hybrid)는 '잡종, 혼성' 등을 의미하는 단어로 서 생물학, 언어학, 전기, 전자, 컴퓨터 등 다양한 분야에 서 여러 의미로 사용되고 있다. 이렇듯 하이브리드 자동 차는 기존의 내연기관 자동차와 전기자동차의 장점만을 모은 것으로, 각각이 가지고 있는 단점을 다른 종으로부 터 보완하는 특징을 가지고 있다.[1]

국제 유가의 지속적인 상승세와 날이 갈수록 심해지는 환경오염 문제 속에서 하이브리드 자동차는 자동차 산업 의 대세로 떠오르게 되었다. 이로 인한 하이브리드 자동 차의 개발 경쟁은 기술 발전과 차종의 다양화를 이끌어
냈으며 소비자들에게는 그만큼 넟은 선택의 폭이 주어지 고 되었다. 세계 유수의 자동차 제조업체에서 다양한 가 솔린 하이브리드 자동차와 디젤 하이브리드 자동차를 내 놓았고, 기존 하이브리드 자동차시장에서 경쟁력이 뒤진 다고 판단한 국내 자동차 회사가 내수 시장 공략을 목표 로 2009년부터 LPG 하이브리드 자동차를 시판하기로 함 으로써 우리나라에서도 하이브리드 자동차의 치열한 경 쟁이 예상된다.

자동차산업이 발달하면서 자동차의 배출가스는 환경 오염 문제를 야기하고 있으며, 그 심각성이 점차 증대됨 에 따라 선진국을 비롯한 각국은 환경규제 강화와 더불 어 배기가스가 없는 전기자동차(Electric Vehicles)의 개 발에 노력을 기울이고 있다. 그러나 전기자동차는 실제 전기에너지를 저장하는 전지모듈의 무거운 중량과 한정 된 에너지원 때문에 주행거리 제약뿐만 아니라 자동차의 구조설계에도 영향을 미치는 단점을 자기고 있어서 그 응용범위가 매우 좁은 실정이다.[2]

본 연구는 지식경제부 지정 공주대학교 자동차의장 및 편의부품 지역혁신센터의 지원에 의한 것입니다 "교신저자 : 최계광(ckkwang@kongju.ac.kr) 
전기자동차에서 가장 큰 문제로 대두되고 있는 1 일 충 전 주행거리 및 충전시간 등을 해결하기 위한 대안으로 하이브리드 자동차가 고안되었으며, 구동 에너지원으로 내연기관 또는 연료전지 등과 축전지를 복합하여 사용하 는 형태이다.

그러나 내연기관 등을 사용하여 하이브리드 자동차를 구성하는 경우 전기자동차에서 가장 큰 문제로 지적되고 있는 1 일 충전 주행거리 등의 한계는 극복할 수 있으나, 북미 일부지역에서 요구하는 무공해 법규를 만족시킬 수 없어 하이브리드자동차는 주로 연비 및 이산화탄소 배출 규제 등에 대응하기 위한 대책으로 선호하고 있다.[3]

하이브리드 자동차의 핵심기술 중의 하나는 자동차 구 동을 위한 적정한 모터의 설계기술이라 할 수 있다. 또한 설계된 모터를 해석함으로 원하는 설계가 이루어 졌는지 검증하고 설계된 모터의 취약점이나 문제점의 발생 등을 사전에 시뮬레이션을 통해서 예측할 수 있어야 한다.[4]

본 논문에서는 이와 같이 중요한 하이브리드 자동차의 구동모터에 사용되는 UV단자를 1 개의 금형에서 2 개의 부품을 공용으로 생산하는 금형을 블랭크전개, 블랭크레 이아웃을 거쳐 스트립레이아웃과 금형설계를 하였다.

\section{2. 본론}

\section{1. 터미널 UV 단자 제품도}

터미널 UV단자의 실제 체결도면은 그림 1 과 같이 구 동모터의 외각을 3 개의 단자가 감싸는 형태이다. 그림 1 과 같이 단자의 연결부위가 다른 부품을 1 개의 금형에서 양산하기로 하였다.
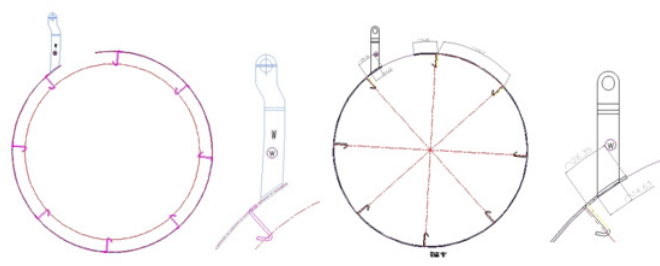

[그림 1] 터미널 UV 단자의 제품도

[표 1] 터미널 UV 단자의 주요사항

\begin{tabular}{|c|c||c|c|}
\hline 소재 두께 & $1.5 \mathrm{~mm}$ & 파일럿 & 간접 파일럿 \\
\hline 재 질 & $\mathrm{Cu}$ & 블랭크 배열 & $\begin{array}{c}\text { 각도배열 } \\
\text { 1열1개 뽑기 }\end{array}$ \\
\hline 클리어런스 & $6 \% \mathrm{t}$ & 스탬핑 방법 & $\begin{array}{c}\text { 피어싱, 노칭, } \\
\text { 벤딩, 파팅 }\end{array}$ \\
\hline 이송피치 & $60 \mathrm{~mm}$ & 전개도 길이 & $594 \times 2534$ \\
\hline 소재 폭 & $594.0 \mathrm{~mm}$ & & \\
\hline
\end{tabular}

\section{2. 블랭크 전개}

블랭크의 전개는 그림 2 와 같이 하였다. $\mathrm{A}$ 단자는 $\mathrm{Z}$ 와 같이 단차가 진 단자이고, $\mathrm{B}$ 단자는 곧게 뻗은 단자이다. 이와 같이 구동모터를 감싸는 부분의 길이는 같으나 단 자연결부위의 길이와 형태가 다른 부품을 1 개의 금형에 서 $\mathrm{A}$ 단자, 또는 $\mathrm{B}$ 단자를 공용으로 양산하기 위해 블랭크 레이아웃을 하였다.

\section{3. 블랭크 레이아웃}

블랭크 레이아웃을 제대로 하기위해서는 이송피치, 잔 폭, 공정수, 이송방향, 블랭크윤곽결정 등을 위해 금형의 구조를 간단히 하고, 금형설치가 용이하며, 금형수리가 쉽도록 고려하여야 한다.[5,6] 최종공정을 배열할 때 선, 후 공정에 따라서 제품이 제대로 양산이 되느냐 되지 않 느냐가 결정이 된다고 사료된다. 표 1 에서 보는 바와 같 이 이송피치는 $60 \mathrm{~mm}$ 이다. 연결핀 벤딩부는 $\mathrm{A}, \mathrm{B}$ 단자 모 두 공용으로 사용할 수 있는 부분이므로 앞 공정에 배열 하고, $\mathrm{A}$ 단자의 연결부위 노칭을 다음에 하고 $\mathrm{B}$ 단자의 연 결부위 노칭을 다음에 하기로 하였다. 마지막으로 노칭으 로 단자를 낙하하는 것으로 블랭크 레이아웃을 완료하였 다. $\mathrm{A}, \mathrm{B}$ 단자의 길이가 $880 \mathrm{~mm}$ 인데, 국내에서 양산되는 소재의 최대폭이 $600 \mathrm{~mm}$ 이므로 광폭으로 단자를 양산할 수가 없게 되어 재료의 이용율을 감안하여 33.5 도로 각도 배열을 하였고, 재료 이용율은 $58.57 \%$ 이었다. 블랭크 레 이아웃은 그림 3 과 같이 하였다.

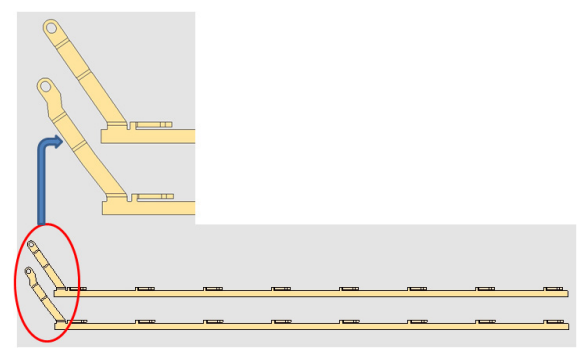

[그림 2] 터미널 UV 단자의 블랭크 전개도

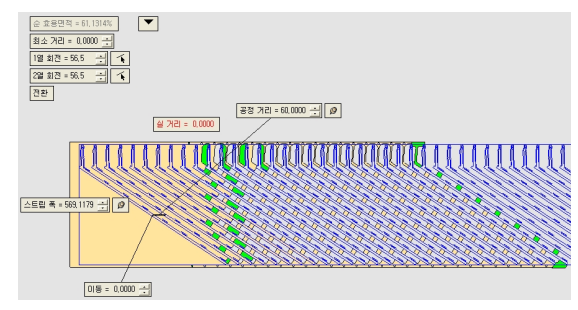

[그림 3] 터미널 UV 단자의 블랭크 레이아웃 


\section{4. 스트립 레이아웃}

\subsection{1 역설계}

블랭크 레이아웃 설계를 완료한 이후에 Cimatron E Die Design을 이용하여 역설계를 하였다.[7,8] 역설계를 할 때 첫 번째로 최종제품의 두께를 없애는 다이스킨을 먼저 하였다. 두 번째는 단자의 3 차 벤딩부를 전개하였 고, 세 번째는 단자의 2 차 벤딩부, 네 번째는 단자의 1 차 벤딩부를 전개하였다. 다섯 번째는 연결핀 3차 벤딩부, 여섯 번째는 연결핀 2 차 벤딩부, 일곱 번째는 연결핀 1 차 벤딩부를 전개하였다. 이와 같이 8 개소의 연결핀 벤딩부 를 전개하여 역설계를 완료하였다.

\subsection{2 스트립 레이아웃}

역설계를 하여 최종결정한 스트립 레이아웃은 29공정으 로 하였다. 표 2는 각 공정별 배열한 최종스트립 레이아웃도 이다. 표 2에서 보는 바와 같이 1공정은, 피어싱, 2 3공정은 아이들, 파일럿, 4-11공정은 노칭, 파일럿, 12 19공정은 노칭 벤딩, 파일럿으로 하였다. 20 27공정은 벤딩 파일럿, 28 29 공정은 노칭, 파팅으로 그림 4와 같이 스트립 레이아웃을 완 성하였다. 스트립 레이아웃도를 바탕으로 피어싱, 노칭, 파 팅공정의 전단력을 계산하기 위하여 Cimatron E Die Design 의 다이포스 기능을 이용하여 총 29 공정의 전단력을 계산하 였다. 다이포스는 그림 5 와 같이 $162,988 \mathrm{kgf}$ 이다.

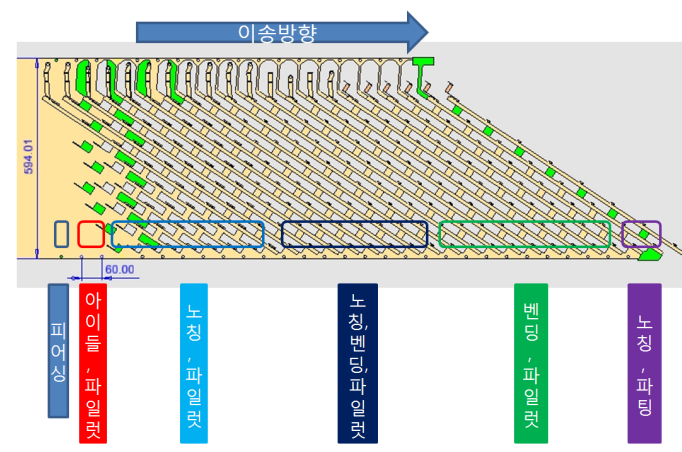

[그림 4] 터미널 UV 단자의 스트립 레이아웃도

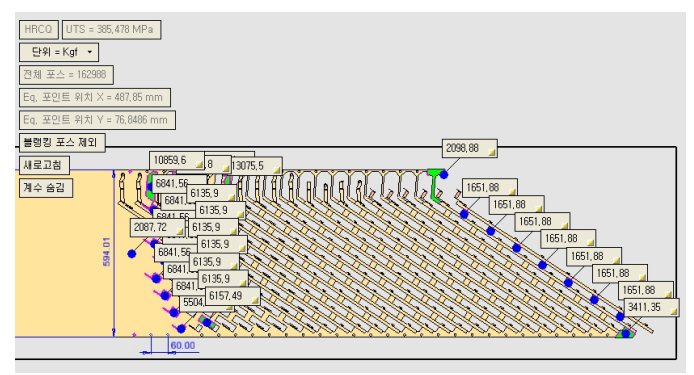

[그림 5] 터미널 UV 단자의 다이포스
스트립 레이아웃상에 2 개의 단자를 노칭하는 부분의 확대도는 그림 6 과 같이 $\mathrm{A}$ 단자는 $\mathrm{Z}$ 와 같이 단차가 진 단 자인데 14 에서 15 공정에서 노칭가공을 하고, $\mathrm{B}$ 단자는 곧 게 뻗은 단자이며 11 에서 12 공정에서 노칭가공을 하였다.

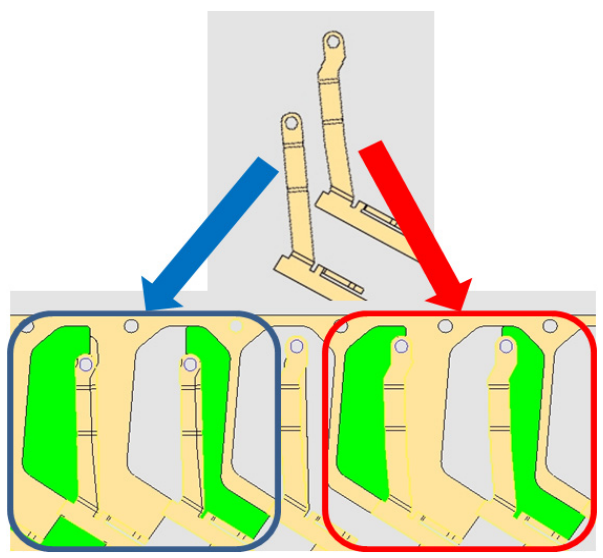

[그림 6] A, B단자의 노칭가공위치

[표 2] 터미널 UV 단자의 최종 스트립 레이아웃 설계

\begin{tabular}{|c|c|}
\hline 스테이지 번호 & 가공공정 \\
\hline \hline 1 & 원형 피어싱 \\
\hline \multirow{2}{*}{$2-3$} & 아이들 \\
\hline \multirow{2}{*}{$4-11$} & 파일럿 \\
\cline { 2 - 2 } & 노칭 \\
\hline \multirow{2}{*}{$12-19$} & 파일럿 \\
\cline { 2 - 2 } & 노칭, 벤딩 \\
\hline \multirow{2}{*}{$20-27$} & 파일럿 \\
\cline { 2 - 2 } & 벤딩 \\
\hline \multirow{2}{*}{$28-29$} & 파일럿 \\
\cline { 2 - 2 } & 노칭 \\
\cline { 2 - 2 } & 파팅 \\
\hline
\end{tabular}

\section{3. 금형설계}

\section{1 터미널 UV 단자 플레이트 설계}

터미널 UV단자의 금형설계시 최종 스트립레이아웃설 계를 한후에 절단윤곽선의 형상에 따라 다이 플레이트 두께에 가중치를 가산하여 다이플레이트의 크기를 결정 한다. 이와 같이 결정한 다이플레이트의 크기는 1,876 * $760 \mathrm{~mm}$ 로 결정하였다. 그러나 소재 이송방향의 다이 플 레이트의 크기가 너무 크므로 3 개로 분할하기로 하였다. 1 차 다이플레이트 크기는 $461 \mathrm{~mm}, 2$ 차는 $500 \mathrm{~mm}, 3$ 차는 
$905 \mathrm{~mm}$ 로 하였다. 이와 같은 비율은 펀치플레이트, 스트 리퍼플레이트, 펀치배킹플레이트, 다이배킹플레이트도 동일하게 하였다. Cimatron E Die Design을 이용하여 3D 로 금형설계한 플레이트는 그림 7 11에 나타내었다.[8,9]

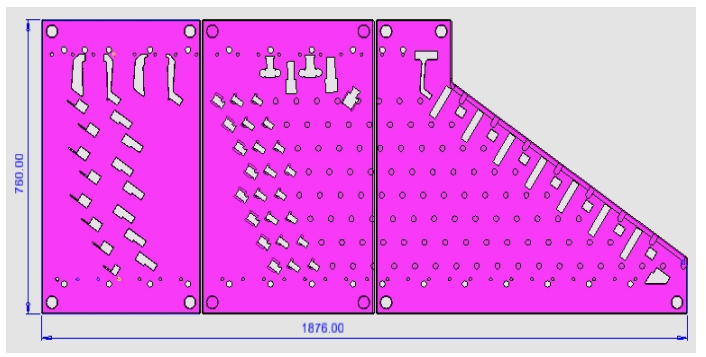

[그림 7] 다이 플레이트

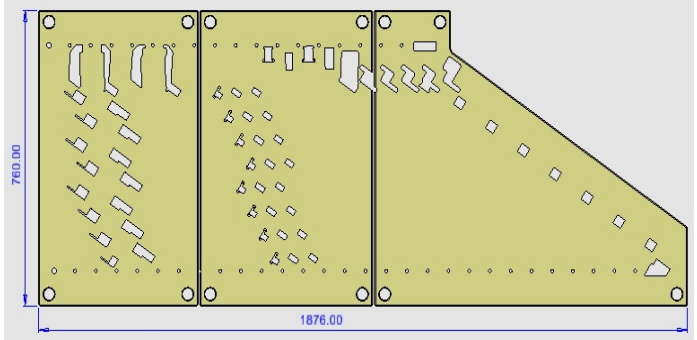

[그림 8] 스트리퍼 플레이트

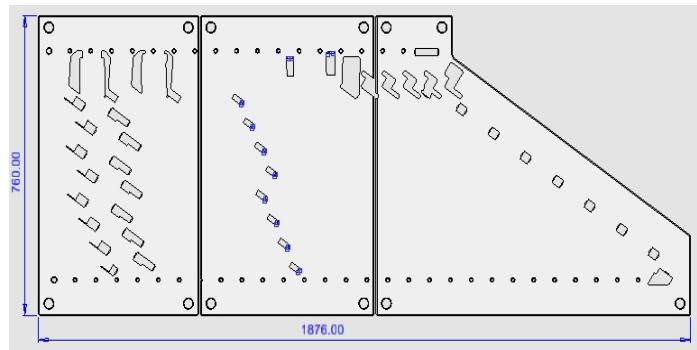

[그림 9] 펀치 플레이트

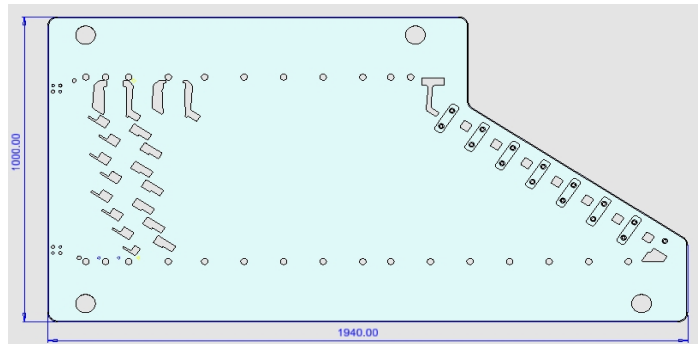

[그림 10] 다이 홀더

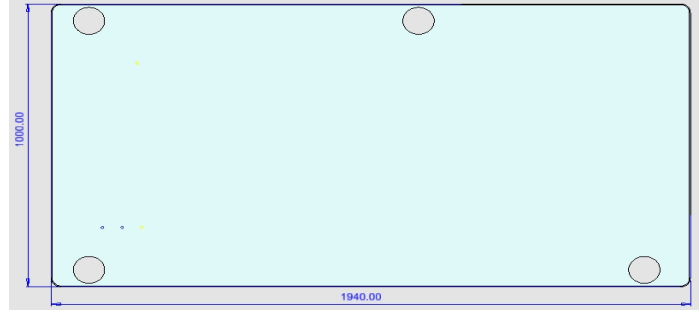

[그림 11] 펀치 홀더

\section{2 펀치 종류별 설계}

그림 4의 스트립 레이아웃도와 표 2의 공정별 순서에 서 보는 바와 같이 피어싱, 노칭, 벤딩, 파팅의 순서로 설 계한 펀치 종류별 설계는 그림 12 16과 같이 하였다.

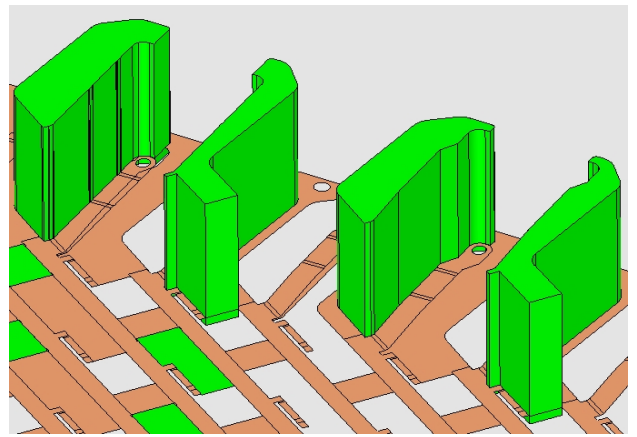

[그림 12] 노칭펀치 설계-1

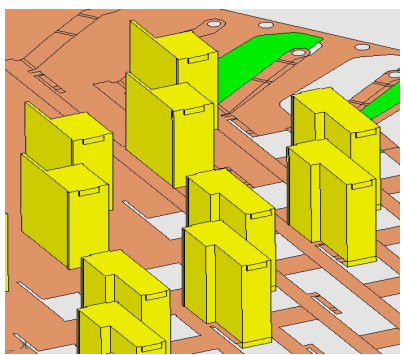

[그림 13] 노칭펀치 설계-2

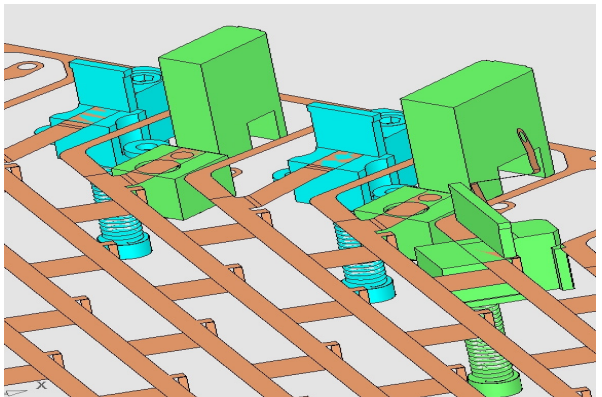

[그림 14] 벤딩펀치 및 다이블록 설계-1 


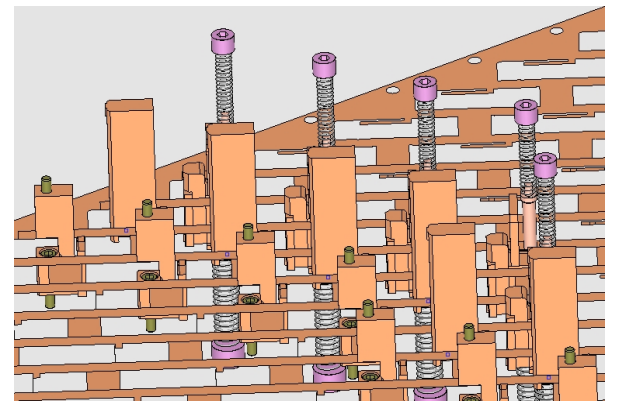

[그림 15] 벤딩펀치 및 다이블록 설계-2

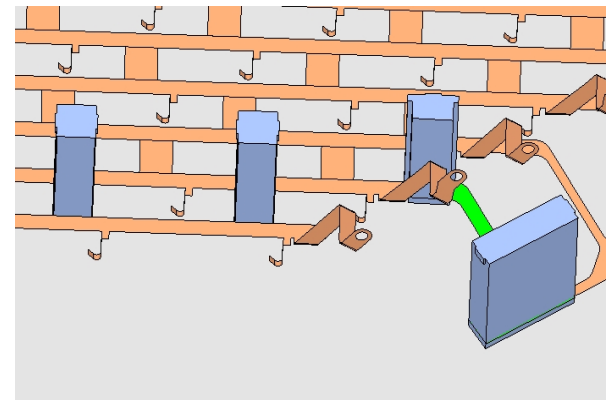

[그림 16] 파팅펀치 설계

\section{3 조립도}

플레이트와 각종 펀치의 설계를 완료한 후에 상형조립 도, 하형조립도, 전체조립도는 그림 17 19와 같이 하였다.

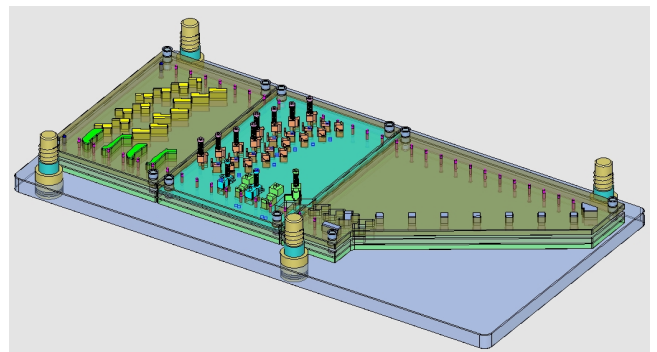

[그림 17] 상형 조립도

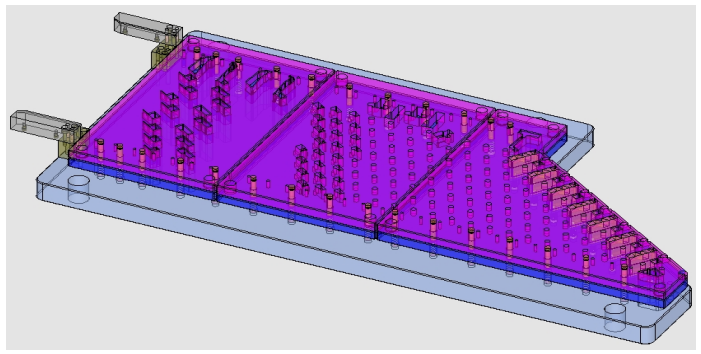

[그림 18] 하형 조립도

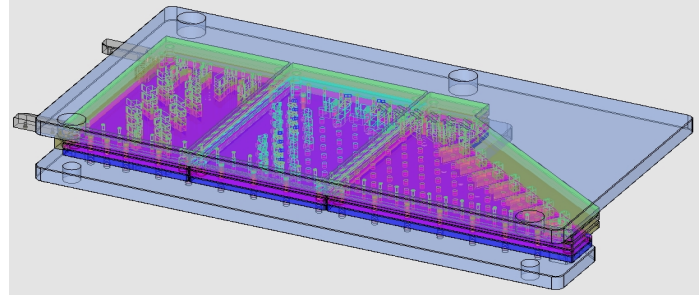

[그림 19] 전체 조립도

\section{4. 결론}

$\mathrm{HEV} \mathrm{UV} \mathrm{단자의} \mathrm{스트립레이아웃과} \mathrm{금형설계에} \mathrm{대하}$ 여 다음과 같은 결과를 얻게 되었다.

1) 하이브리드 자동차 시장이 본격화 되는 시기에 신 차에 적용이 되는 UV단자의 스트립 레이아웃설계 에 관한 것이다.

2) 2 개의 단자를 하나의 금형에서 공용으로 설계하여 양산하기 위해 스트립레이아웃을 하였고 재료 이용 률은 $58.57 \%$ 로 하였다.

$3)$ 현재 국내에서 시판되는 최대 소재폭 $(600 \mathrm{~mm})$ 을 맞 추기 위해 블랭크 레이아웃을 33.5도로 하였다.

4) 전체 스트립 레이아웃 공정수를 29공정으로 최적화 하였고 이송방향의 금형크기가 커서 3 개로 분할하 여 금형설계를 하였다.

\section{참고문헌}

[1] 양인범, "HEV용 전장부품 기술동향”, 전력전자학회 지, Vol 12, No 5, pp. 37-40, 2007.

[2] 이동준, 이예지, 허은녕, "국내 보급 예정 하이브리드 자동차의 유형별 편익 고찰", 한국신재생에너지학회 논문지, Vol 4, No 2, pp. 52-60, 2008.

[3] 이재용, 이백행, “전기모터를 구동 동력원으로 하는 자동차의 개발동향", 전력전자학회지, $\mathrm{Vol} 5$, No 2, pp. 42-46, 2004.

[4] 문재원, 안진우, “하이브리드 자동차 구동용 $65 \mathrm{~kW}$ 급 SR Motor의 설계”, 전기학회논문지 전기기기 및 에너 지변환시스템부문, Vol 54, No 8, pp. 358-363, 2005.

[5] 김세환, “도해 프레스 금형설계 데이터북", 대광서림, pp.1-4 1-84, 2006.

[6] 김세환, “프레스금형설계기준”, 한국금형정보센타, pp.48 122, 1992.

[7] 김세환, 안종민, “프로그레시브 금형설계기술”,기전연 
구사, pp.101 145, 1995.

[8] Cimatron. Co., "Cimatron E Die Design Guide".

[9] 최계광, 조윤호, "HEV UV단자의 스트립 레이아웃설 계에 관한 연구”, 2010년 한국산학기술학회 춘계 학 술발표논문집, pp.1166 1168, 2010.

\section{최 계 광(Kye-Kwang Choi)}

[종신회원]

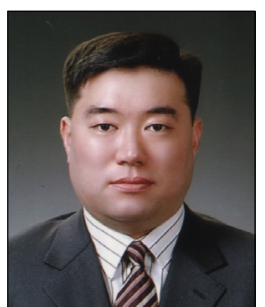

- 1993년 2월 : 부산공업대학교 금 형공학과 (공학사)

- 1995년 8월 : 국민대학교 대학원 기계설계학과 (공학석사)

- 2005년 2월 : 국민대학교 대학원 기계설계학과 (공학박사)

- 2005년 8월 : (주) 현대배관 기 술부장

- 2010년 12월 : 공주대학교 기계자동차공학부 조교수

<관심분야>

3차원 금형설계, 와이어 컷 방전가공

\section{김 세 환(Sei-Hwan Kim)}

[종신회원]

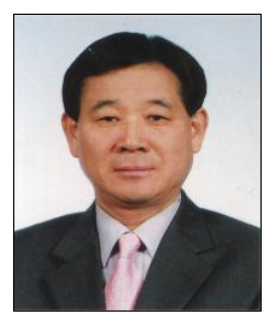

- 1971년 2월 : 수도공과대학 기계 공학과 (공학사)

- 1986년 2월 : 국민대학교 대학원 기계설계학과 (공학석사)

- 1997년 2월 : 국민대학교 대학원 기계설계학과 (공학박사)

- 1979년 2월 : (주) 삼아 공장장

- 1982년 3월 : 천안공업대학 금형설계과 교수

- 2010년 12월 : 공주대학교 기계자동차공학부 교수

<관심분야>

프레스 금형, 단조가공, 금형열처리

\section{조 윤 호(Yun-Ho Cho)}

[정회원]

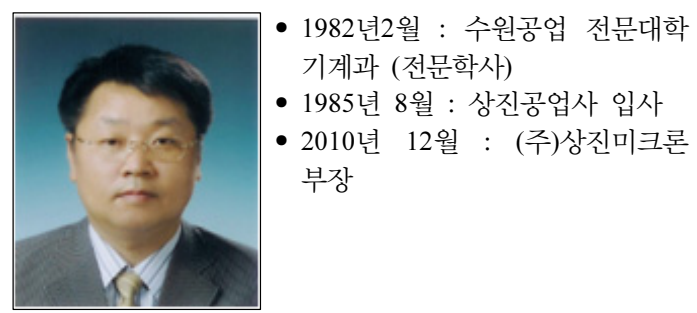

<관심분야>

프레스 금형, 공정설계 